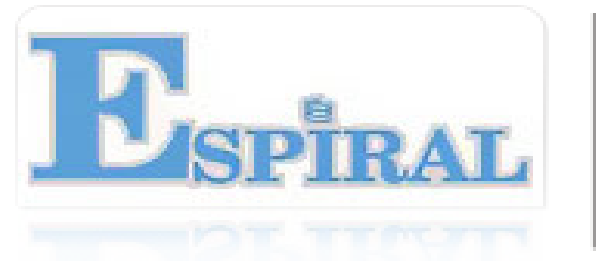

\title{
Espiral
}

ISSN: 1665-0565

espiral@fuentes.csh.udg.mx

Universidad de Guadalajara

México

Arteaga del Toro, Leonora

Governing the World: The History of an Idea

Espiral, vol. XX, núm. 58, septiembre-diciembre, 2013, pp. 255-260

Universidad de Guadalajara

Guadalajara, México

Disponible en: http://www.redalyc.org/articulo.oa?id=13831462009

- Cómo citar el artículo

- Número completo

- Más información del artículo

Página de la revista en redalyc.org

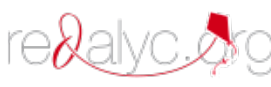

Sistema de Información Científica

Red de Revistas Científicas de América Latina, el Caribe, España y Portugal Proyecto académico sin fines de lucro, desarrollado bajo la iniciativa de acceso abierto 


\section{Governing the World: The History of an Idea}

Leonora Arteaga del Toro•

En el sentido platónico, una idea es una abstracción que condensa una experiencia individual. "Gobernar el mundo" —o lo que actualmente se conoce como tal, ya que esto ha variado según la evolución de la civilización occidental- ha sido una idea que ha conducido a los líderes de las potencias dentro del sistema internacional a buscar el poder sobre sus vecinos, su región geográfica o, en su defecto, especialmente a partir del siglo XX, sobre el orbe.

La idea de "gobernar el mundo" representa la necesidad de evitar la anarquía y el caos que por naturaleza causa el hombre en su lucha por sobrevivir y alcanzar sus metas; misma que suele representar una amenaza para sus prójimos. Si se traslada esta lucha de supervivencia al Sistema Internacional, se observa que existe un grupo de individuos que luchan por sobrevivir y obtener el poder uno sobre el otro, sea para protegerse o para expandirse, conquistando nuevos territorios.

Ahora bien, registrar la historia de la idea de "gobernar el mundo" sin "tomar partido", es decir, sin escribirla como un vencedor, es una tarea que requiere habilidad y paciencia. En la

Profesora de asignatura de la Universidad Autónoma de Baja California. leonoraarteaga@ gmail.com obra de Mark Mazower que aquí se reseña, se ofrece al lector un viaje a través de la evolución del Sistema Inter- York.

Mazower, Mark (20I2).Governing the World: The History of an Idea. Penguin Press: Nueva 
nacional, desde la óptica de cómo resolver el problema de la anarquía que reina en el Sistema; lo cual, por otro lado, es un problema que desde la caída del Imperio Romano ha preocupado a quienes se han encontrado a la cabeza de los distintos modos de organización del Sistema.

Si se compara esta obra de Mazower con La diplomacia de Henry Kissinger (2001), se puede ver que esta no inclina su análisis hacia ninguna teoría de las relaciones internacionales, puesto que regresa al origen de la disciplina: la historia diplomática; así es como su examen se remonta más allá del periodo de la Guerra Fría e incluye en él las dinámicas del Sistema después del 11 de septiembre de 2001 y lo extiende hacia la crisis del euro, ofreciendo un complemento al análisis de Kissinger del mundo de la posGuerra Fría, permitiendo así que el lector haga los juicios de valor más adecuados a su formación teórica y a su pensamiento ideológico.

A diferencia de su obra Dark Continent, Mazower (2000) ofrece en este libro —en lo que respecta al análisis del continente europeo - una apertura que sitúa a Europa más allá del contexto regional. Es decir, la sitúa en el contexto internacional, ya que observa la relación que ha tenido con Estados Unidos a partir del Concierto de Europa. De esta manera, ofrece al lector un punto de comparación entre ambos actores y sus estilos de manejar la hegemonía del Sistema Internacional, con lo cual el lector puede notar que el origen de Estados Unidos es muy distinto del de la Unión Europea, ya que las circunstancias que rodearon sus orígenes son diferentes, del mismo modo que lo son las causas que lo han llevado a tener la hegemonía del Sistema. Dicho lo anterior, se puede afirmar que esta obra ofrece argumentos sobre el futuro de la Unión Europea y su rol dentro del Sistema, tanto a los federalistas como a los supranacionalistas europeos. 
Ahora bien, si se coteja esta obra con Postwar de Tony Judt (2005), se puede notar que la narrativa de Mazower es tan concisa como la de Judt; sin embargo, este último conduce al análisis de las circunstancias que llevaron a Europa a perder la hegemonía del sistema internacional desde antes de la I Guerra Mundial, así como las circunstancias que condujeron al proceso de integración de Europa. Aunque ambos autores exploran estas circunstancias, se puede observar en la obra de Judt el planteamiento de un análisis hacia el interior, mientas que en la de Mazower se nota el mayor interés en las circunstancias externas que llevaron a Europa a comenzar este proceso. Con todo, los dos muestran cómo las preferencias europeas han cambiado respecto a la tenencia de la hegemonía mundial.

Como ya se mencionó, Mazower hace un corte entre la hegemonía europea y la hegemonía estadounidense; situación que también ofrece un complemento a la obra de Kinzer (2007), Overthrow. Dando explicación a las circunstancias que llevaron a Estados Unidos a buscar el liderazgo mundial, el autor expone cómo esta nación se ha comportado como hegemón y paralelamente ofrece un panorama de lo que pudiera ser el futuro del mundo, partiendo de los acontecimientos que han dado forma al Sistema Internacional actual.

Respecto del análisis de Estados Unidos y su búsqueda de la hegemonía mundial, cabe señalar que Kinzer hace un análisis (al igual que Judt) hacia el interior, mientras que Mazower se concentra en el exterior. Con lo dicho se resaltan las diferencias entre los autores discutidos; aunque estas también se encuentran en las narrativas: en tanto que Kinzer utiliza el estilo de la crónica periodística, Judt se sirve de la del documental. Pero retomando a Mazower, conviene resaltar que el autor, cuando habla del mundo posterior al 11 de septiembre y la crisis financiera europea, concluye diciendo que la idea de gobernar al mundo ya es 
cosa del pasado, puesto que se han superado las formas antiguas de las alianzas y los equilibrios de poder, que en un momento dado no respetaron la soberanía de varias naciones y los problemas generados fueron resueltos mediante la creación de organismos supranacionales que vigilan el orden y el respeto de la legislación internacional.

A partir de tal aseveración, el lector notará que el autor - a pesar de no sesgar su análisis hacia ninguna teoría de relaciones internacionales en específico- nos ofrece un argumento de carácter neoliberal. De manera que se puede observar que la propuesta del autor es la de transitar desde la idea de "gobernar el mundo" hasta la de la "gobernanza global", como forma de solucionar el problema y los conflictos generados por la anarquía existente dentro del Sistema Internacional. Es decir, transitar del poder en manos de pocos, al poder en manos de todos; lo cual representa una apertura y una evolución en el carácter con el que se mantiene el orden dentro del Sistema. Esto último quizás represente los efectos positivos de las transiciones a la democracia ocurridos a partir de 1848, así como el ideal humano de vivir en un clima de paz.

Como aportación propia, lo que este libro ofrece al internacionalista es una visión más amplia de cómo han desaparecido y se han creado los distintos modelos de organización internacional por los que ha pasado el Sistema desde el final de la Revolución Francesa hasta la actualidad, así como la importancia de las circunstancias y del contexto histórico que influyeron en su creación. De la misma manera, el trabajo de Mazower contribuye a que el internacionalista comprenda cómo ha cambiado la idea de "gobernar el mundo"-especialmente después de la I Guerra Mundial - y cómo los acontecimientos históricos coyunturales logran cambiar la visión del ser humano, toda vez que este sea capaz de vislumbrar el "antes" y de compararlo con el "después". 
El objetivo de este libro es conducir al lector a través de los distintos escenarios de la política internacional a través del tiempo, para que este haga sus propios juicios de valor en relación con las preguntas de por qué fracasaron, por qué tuvieron que ser remplazados, por qué no funcionaría regresar a ellos y qué lecciones se pueden aprender y aplicar para que haya orden dentro del caos. Quizás la idea de "gobernar el mundo" ya no represente el advenimiento de eventos bélicos catastróficos, como los ocurridos durante los últimos 300 años, de los cuales el más reciente la II Guerra Mundial. Aun así, esta idea sigue presente en las formas de conducir las agendas internacionales y las políticas exteriores de quienes tienen el poder. La idea de "gobernar el mundo" es algo que va más allá de conquistar territorios y dominar pueblos: es una representación de la naturaleza egoísta del ser humano y su lucha por sobrevivir, lograr sus fines y sortear las amenazas que trae consigo la anarquía en la que ha vivido. Al trasladar esta representación de la naturaleza humana al Sistema Internacional, se observa el mismo comportamiento entre las naciones y se ve el reflejo en sus líderes.

En conclusión, esta obra presenta un análisis de la evolución de la hegemonía internacional y cómo esta ha ido cambiando debido a las coyunturas históricas. Es una obra con la cual se puede comenzar a comprender cómo se ha dado esta evolución. Con ella el lector comenzará un viaje que tiene como destino final explorar las circunstancias históricas que han acompañado esta evolución, así como los hechos y acontecimientos históricos que han conducido a los teóricos a construir la disciplina de los estudios internacionales. 
Bibliografía $\quad$ Judt, T. (2005). Postwar: A History of Europe since 1945. Nueva York: Penguin Books.

Kinzer, S. (2007). Overthrow: America's Century of Regime Change from Hawaii to Iraq. Nueva York: Times Books. Kissinger, H. (200I). La diplomacia (trad. de Mónica Utrilla) $\left(2^{\mathrm{a}}\right.$ ed.). México: Fondo de Cultura Económica.

Mazower, M. (2000). Dark Continent: Europe's Twentieth Century. Nueva York: Vintage Books. 